\title{
Effective flood risk visualisation
}

\section{Sarah Ellen Percival ${ }^{1}$ (D) $\cdot$ Mark Gaterell $^{2} \cdot$ David Hutchinson ${ }^{3}$}

Received: 26 September 2019 / Accepted: 8 July 2020 / Published online: 18 July 2020

(c) The Author(s) 2020

\begin{abstract}
The effective communication of flood risk offers the opportunity to ensure communities can adapt and respond appropriately to changing local conditions. At a time of diminishing resources, such local responses, which can empower communities and make them more resilient to uncertain future flood events, are vital. The most general and accessible type of flood communication are flood risk visualisations, i.e. pre-prepared emergency flood maps. However, evidence suggests there is much we can do to improve their ability to communicate the complexities of flood risk to a range of stakeholders. This paper considers the development of flood risk visualisation approaches in the UK, presenting findings from a series of targeted workshops over twelve months, where the needs and criteria of stakeholder groups for effective flood risk visualisation were assessed via co-creative processes. Key stakeholders included local authorities, emergency responders, vulnerable homeowners, Environment Agency, business owners and, crucially, communities. These users need certain requirements to be considered in order for future flood risk visualisation to be effective, in particular simplicity, a central hub of information, different visuals available for the same data sets/problems, different maps available for different users, consistent terminology and integrated community knowledge (e.g. local flood groups/help).
\end{abstract}

Keywords Flood risk · Mapping $\cdot$ Visualisation $\cdot$ Co-creation $\cdot$ Communication

Sarah Ellen Percival

S.E.Percival@ljmu.ac.uk

Mark Gaterell

mark.gaterell@port.ac.uk

David Hutchinson

david.hutchinson@port.ac.uk

1 School of Biological and Environmental Sciences, Liverpool John Moores University, Liverpool, UK

2 School of Civil Engineering and Surveying, University of Portsmouth, Portsmouth, UK

3 Faculty of Technology, University of Portsmouth, Portsmouth, UK 


\section{Introduction}

It is difficult and expensive to reduce flood risk as the causes and management of flooding are complex (Pitt 2008; Bracken et al. 2016; RSPB 2016; Warburton 2016). Yet there are still opportunities to improve our flood risk management practices and enhance a community's ability to cope with external stresses and disruptions (its resilience) (Adger 2006), especially the communication of flood vulnerability (physical and socioeconomic characteristics or wider deprivation within areas (Maantay and Maroko 2009; Wilson et al. 2014; Percival et al. 2018) and risk [interaction of hazards and an area's/ community's vulnerability (Percival and Teeuw 2019)]. Communities need to become less vulnerable to increasingly likely hazards if we are to manage flood risk effectively, and it is the response of the community itself that, to a large degree, determines vulnerability (Cornwall Council 2015; Rollason et al. 2018). To improve community responses, communication and dissemination of flood risk are vital (IPCC 2012; Haer et al. 2016). Simply identifying vulnerable areas is insufficient to successfully mitigate risk and minimise impact. There is also a need for high levels of awareness via effective communication. Yet currently, public awareness is very low (Rollason et al. 2018), despite vast amounts of flood risk information readily available via governments and organisations (Haer et al. 2016). In fact, recent surveys by the Environment Agency (2016) regarding flood risk identified that only $7 \%$ of the public realised that they and their properties were at risk of flooding (House of Commons 2016). Furthermore, many did not understand the potentially devastating long-term consequences flooding can have, including having flood response measures ready in place (Percival and Teeuw 2019).

Effective communication plays a key part within successful flood management/resilience approaches (Pitt 2008; Hagemeier-Klose and Wagner 2009; Meyer et al. 2012; Wicks et al. 2014; Rollason et al. 2018), particularly flood risk maps (visualisation) (Porter and Demeritt 2012). Successful flood risk visualisation enhances awareness for the need for action (individual, local and national). Prompting communities to develop strategies to ensure local-level resilience is advanced, i.e. appropriately adapting and responding to changing local conditions (de Moel et al. 2009; Butler and Pidgeon 2011; Rollason et al. 2018; Bodoque et al. 2019). The House of Commons (2016) has stated that flood risk agencies must find clearer ways of explaining flood risk, to simultaneously spur householders and businesses to effectively prepare for floods and to inform public views on national and local flood risk strategies.

However, flood risk information can be complex and current practices of flood risk mapping can be difficult to understand. Common approaches to flood hazard/vulnerability/risk mapping have mostly been technical, map-based and often statistical (Sciencewise 2014), generating maps with contents that regularly do not match end-user requirements (Warburton 2016) or visualised in a way that cannot be easily understood (Meyer et al. 2012). Hence, flood hazard/vulnerability/risk maps are predominantly seen as an informative tool rather than a communicative tool, resulting in a real challenge to present this information in a way that is both meaningful and helpful (i.e. prompts communities to take action) (Sciencewise 2014; Warburton 2016). The research presented in this paper aims to address these issues and help communities become more resilient to flood risk (defined here as a combination of hazard and vulnerability) by exploring approaches to enhance the communication of flood risk in the UK, particularly focusing on the use of visualisation techniques (predominantly flood risk mapping) that are 
able to capture and integrate the preferences, expectations and experiences of local and national flood stakeholders into the decision-making process.

To assess the needs and associated necessary criteria of stakeholder groups for effective flood risk visualisation, co-creative processes were applied in a series of targeted workshops over twelve months. Co-creation is viewed as a new approach within the context of climate change and involves community and expert stakeholders contributing their knowledge and ideas, within a planning and/or implementation process (Wamsler 2016), i.e. a mode to jointly produce knowledge or a mutually valued outcome (Wamsler 2016; Amann and Rubinelli 2017; Anderson and Hardwick 2017), in this case increasing flood resilience. Expert knowledge per se is increasingly seen as insufficient for informing decisions concerned with specific local contexts for flooding (Cinderby and Forrester 2005; Eden et al. 2006; Douglas et al. 2010; Maskrey et al. 2016). It is now recognised that in order to deliver sustainable solutions, decision-making processes need to adopt a participatory paradigm, to ensure those possessing certified expertise and situated knowledge can be effectively engaged in the co-creation of the information necessary to inform decisions (Callon 1999; Maskrey et al. 2016).

One of the challenges inherent in co-creative approaches is identifying an effective mechanism through which to engage. Currently, there is no absolute established mechanism or technique for flood communication to be used to educate those involved that is perceived as successful. Likewise, there is no clear pathway for consultation ensuring that needs, opinions and ideas from flood stakeholder group members are included. For the purpose of this research, workshops were used as they offered an opportunity and platform to close these gaps. They have also successfully been used in previous national participatory projects as a 'vehicle' when trying to identify, co-create and implement sustainable flood management. This includes a number of the DEFRA Community Pathfinder Schemes (2015) and flood management schemes in Hebden Bridge (2015), West Yorkshire (2007) and Pickering, North Yorkshire (2007). They offered a space for the community and expert stakeholders to learn directly and indirectly from one another, building capacity and a new place for dialogue about this particular context ( Frantzeskaki and Kabish, 2016), building consensus and providing a window for 'open public framing' of flood vulnerability and hazards (Maskrey et al. 2016) that allows flood risk to be understood by all, and not as a series of unchallengeable facts.

By adopting co-creative processes through a series of workshops, local and expert knowledge and experience (including members of Local Resilience Forum (LRF), Environment Agency (EA), local councils, National Flood Forum (NFF), emergency services, Flood Action Groups (FAGs) and crisis and disaster management postgraduate students) were used to identify critical flood risk information users and the specific criteria needed by these users, that can be modelled and incorporated into new flood risk visualisations. The intention being to ensure user-specific needs drove the development of effective flood risk visualisations (maps), thereby improving our ability to communicate these complex problems. 


\section{Methodology}

\subsection{Workshop program}

Through the UK Urban Flood Risk Communication workshops (Fig. 1), stakeholders' perceptions, ideas and designs of successful flood risk visualisation were captured, visualised and assessed co-creatively. A key task was working with local and national networks of flood stakeholders to ensure appropriate workshop participants were identified. Pre-existing relationships with flood stakeholder groups and the NFF (e.g. local FAGs, resilience forums, residents/business owner campaign groups) were utilised to ensure a wide range of flood group members (with varying understanding of different perceptions of flood risk) were present at the workshops, minimising bias and marginalisation of flood groups (Maskrey et al. 2016).

The first set of workshops $(1 \mathrm{a}-\mathrm{c})$ aimed to identify the nature of key flood risk communication criteria and themes, that new visualisation techniques should take, including who are the critical users. The second set of workshops (Workshop 2) reflected on the criteria and themes for effective flood risk visualisation set in Workshops 1a-c, including user suitability, i.e. different criteria or aspects of that criterion that may only be required for certain users. The final workshop (Workshop 3) involved a survey of the visualisation criteria and techniques identified as warranting further appraisal, i.e. their ability to disseminate flood risk effectively. This included their significance and probability of occurrence, where (scale/level) they should be developed (informed (data collection), coordinated and

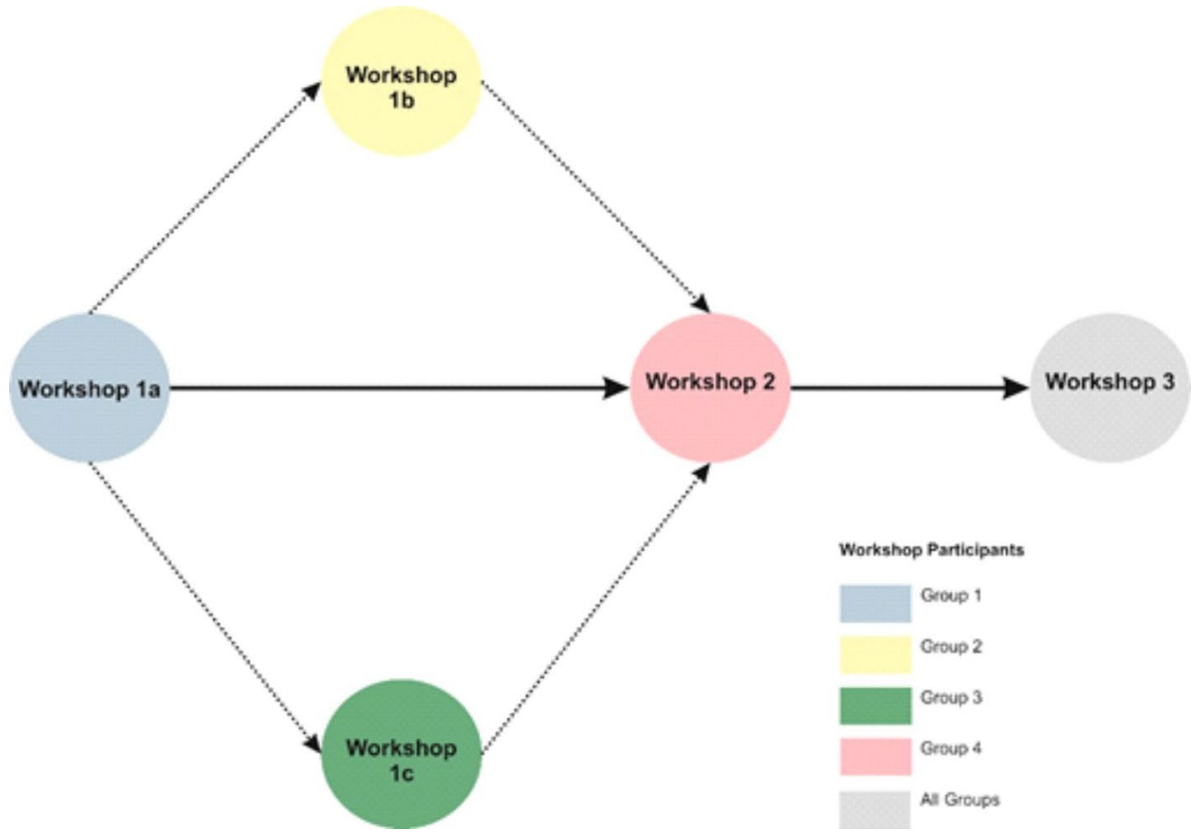

Fig. 1 UK Urban Flood Risk Communication Workshop Program. Group 1—national and local flood risk managers, local flood resilience members, academics; Group 2-emergency services personnel and emergency management students; Group 3-local FAG members; Group 4-LRF members 
delivered) and what else is needed to ensure they occur. This paper solely focuses on the proceedings and results of the first phase of workshops (Workshops 1a-c (November 2017) and Workshop 2 (between April and June 2018)), in order to highlight the breadth of identified flood risk visualisation users and their many specific requirements.

\subsection{Workshops 1a-c}

The aim of Workshops 1a-c was to ascertain key flood risk visualisation users and explore and model pivotal criteria/themes for effective flood risk visualisation, identified by different stakeholder groups (Group 1-national and local flood risk managers, local flood resilience members, academics (15 participants); Group 2-emergency services personnel and emergency management students (40 participants); and Group 3-local Flood Action Group (FAG) members (6 participants)), via three exercises. Specific objectives of Workshops 1a-c included, a) recruitment of participants through pre-existing relationships, established via University of Portsmouth and NFF; b) allocation of flood stakeholders into appropriate groups; c) identification of key flood risk visualisation users via Groups 1, 2 and 3; and d) establishment of flood risk communication criteria that pre-existing/new flood risk visualisation techniques should address via Groups 1, 2 and 3. Workshops 1a-c ran over a three-week period, and the same material/exercises were used in each session, ensuring Groups 1, 2 and 3 witnessed and participated in the same material and activities.

Before any exercises took place, all groups were presented with an array of examples. The same examples were used in each workshop. They predominantly were in the form of freely available flood risk/hazard maps that were either two-dimensional (2D) or threedimensional (3D), thus ensuring that participants understood the term flood risk visualisation and the different formats they can be presented in. Each group then participated in Exercises 1, 2 and 3, run via an independent facilitator:

- Exercise 1: Flood risk visualisation users

- Exercise 2: What works, what could be better and what's missing?

- Exercise 3: Common flood risk visualisation themes and criteria

Exercise 1 was both an individual and group event. Each participant separately noted as many flood risk visualisation users of which they could think. In groups, participants then collated their identified users under main flood risk visualisation user groups, e.g. emergency responders, local authorities (LA) (Fig. 2). In Workshops 1a and 1c, due to the number of participants present (Group 1-fifteen participants, and Group 3-six participants), the latter activity was done together via the facilitator (Fig. 2).

Exercise 2 was a group activity where Workshops 1a-c participants were split into smaller groups and asked to evaluate the flood risk visualisation examples shown during the session (paper copies were also available), or other examples they knew of, whilst considering the questions what's missing, what's working and what could be better? Groups then listed (bullet points) what they felt was currently working, missing or could be better within current flood risk visualisation practices. Groups worked on each question in turn and reflected on prior groups' points, adding more if necessary, ensuring each group had answered each question.

Exercise 3 was a facilitator led group (Group 1, 2 or 3 ) discussion, where all participants from each group considered which points (based on everything they had heard, seen and identified in the workshop) were a priority and the key criteria needed for flood risk 
Fig. 2 Workshops 1a-c participants (Groups 1, 2 and 3) partaking in facilitator led Exercise 1key flood risk visualisation users

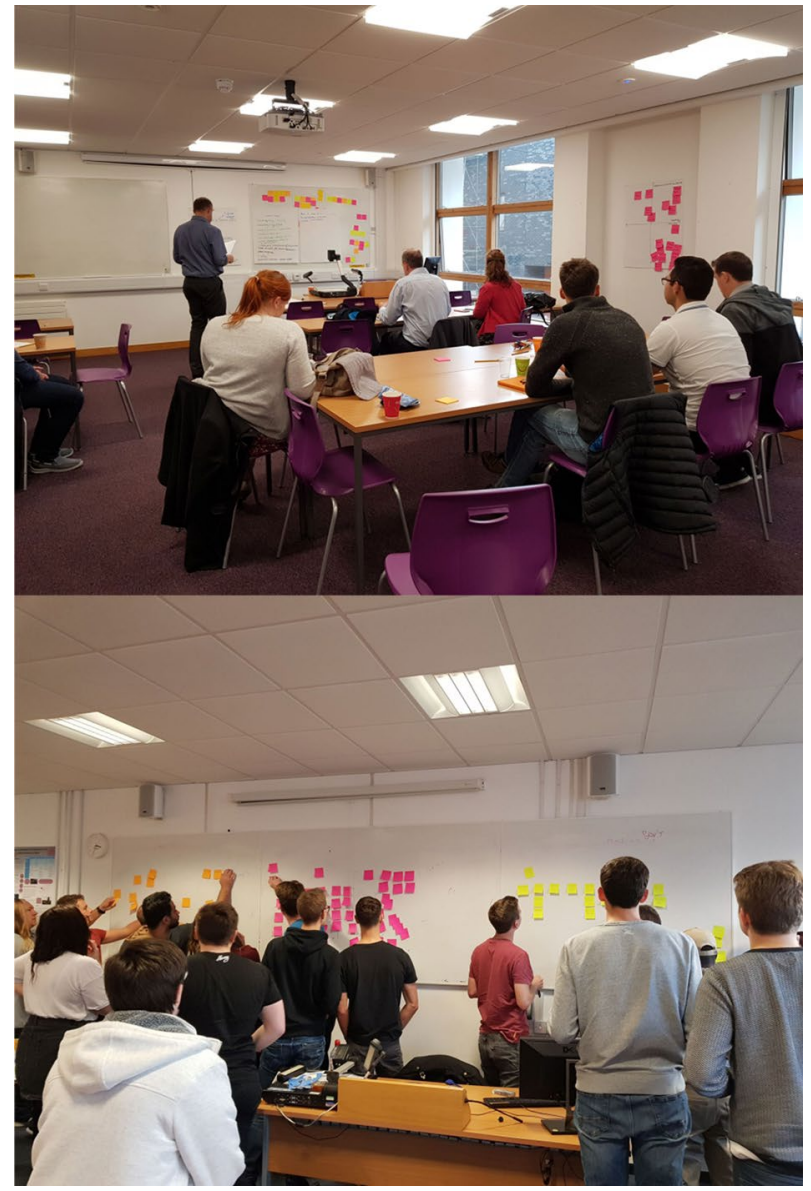

visualisation to be understood, effective, and help facilitate change, i.e. increase flood resilience. Key points were called out and discussed within the group (1, 2 or 3), and only those agreed upon by the entirety were noted by the facilitator as warranting further appraisal.

\subsection{Workshop 2}

It was originally anticipated that the approaches within Workshops 1a-c would develop the criteria for effective flood risk visualisation, using the city of Portsmouth (UK) to pilot this study, resulting in a set of Portsmouth flood risk objectives that visualisation techniques should address whilst producing different visualisations (urban flood vulnerability and risk map/visualisation examples) that would reflect Group 1, 2 and 3's requirements and experiences. However, Workshops 1a-c formed an iterative process through which the research objectives and future workshop activities were refined to reflect the development of the criteria set by the stakeholders involved. The criteria set in Workshops $1 \mathrm{a}-\mathrm{c}$ were in fact of a much more general nature, resulting in the research objectives and direction of Workshop 2 and 3 to change. Rather than visualisation specifics such as data/technical aspects/techniques, or specific local issues 
related to Portsmouth, preferences and needs of the workshop participants were particularly heterogeneous and concentrated on overall aspects of national flood risk visualisation, highlighting that the complexity and issues of flood risk communication are still at a national level and could not be captured and integrated into local examples. Therefore, the aim of Workshop 2 became a reflection of the criteria for effective flood risk visualisation set by Groups 1, 2 and 3 from Workshops 1a-c. Specific objectives included: (a) development and execution of Workshop 2 with LRF members (Group 4, Fig. 1); (b) evaluation (Exercise 4) of the flood risk visualisation criteria set by Groups 1, 2 and 3, i.e. which criteria do key flood risk visualisation users need and what should that encompass?

Workshop 2 entailed LRF members participating in Exercise 4: Questionnairewhich criteria do each key flood risk visualisation user (defined in Workshops 1a-c) need, and what should that entail? This ran at LRF offices to maximise participation and resulted in 21 responses. However, due to exercise 4's popularity, it was also made into an online survey (www.SurveyMonkey.co.uk) and sent to other LRF members to complete, gaining a further 19 responses. Participants included members of Southampton City Council, Ministry of Defence, Environment Agency, Winchester City Council, East Hampshire District Council, Hampshire Fire and Rescue, Environment Agency (EA), Met Office, Voluntary Services, Eastern Solent Coastal Partnerships, Hampshire County Council, Public Health England, British Red Cross, Wightlink Ferries, and Water Search and Rescue Team (WSART).

Workshop 2 took place at Hampshire County Council Offices in Winchester (LRF headquarters), and participants were members of LRFs (Group 4). Exercise 4 was an individual activity and involved participants undertaking a questionnaire either on site or online. Participants were asked whether each flood risk visualisation user (identified in Workshops 1a-c) actually needed the top flood risk visualisation criteria selected in Workshops $1 \mathrm{a}-\mathrm{c}$, i.e. yes, no or not sure. If the answer was yes or not sure, further questions were asked, e.g. for Criteria 1, user-driven maps-what should be made available to that user (i) simple maps (e.g. flood zone and risk level); (ii) very detailed/ complex maps (e.g. flood contexts including timing, seasonality); (iii) rest centres and escape routes; or (iv) historical maps. All sub-questions within each table, for each criterion, were based around points identified by participants in Workshops 1a-c, Exercises 2 and 3. Participants also had the opportunity to write down any extra points/ comments that were not represented in the tables for each criterion.

\section{Workshop findings}

\subsection{Exercise 1: key flood risk visualisation users}

All the results from Exercise 1 were collated from Workshops 1a-c (Table 1), and the key flood risk visualisation users were determined by popularity (i.e. flood risk visualisation users listed the most). LA was seen as the key user for flood risk visualisation, with emergency responders coming second, and public coming third. Unusually, the group vulnerable homeowner (elderly, renters and agricultural) was highlighted, stressing an underlying understanding of vulnerability by the participants. 
Table 1 Workshops 1a-cresults (all groups) Exercise 1: Key flood risk visualisation users, listed by popularity (most votes at the top (local authorities) to least votes (business owners))

\begin{tabular}{ll}
\hline Key flood risk visualisation user groups & Subgroups \\
\hline Local authorities (LA) & Flood risk managers \\
& Coastal engineers \\
& Planners \\
Emergency responders & Fire \\
& Police \\
& Ambulance \\
General public & Communities \\
& Tourists \\
Vulnerable homeowner & Elderly \\
& Renters \\
& Agricultural, i.e. farmers \\
Environment Agency (EA) & Basement owners \\
Business owners & Environment Agency (EA) \\
& Large \\
& Local \\
& Investor \\
\hline
\end{tabular}

\subsection{Exercise 2: What works, what could be better and what's missing?}

This was a popular exercise and resulted in both similar and varied responses. Collated results from Workshops 1a-c, Exercise 2, are presented in Table 2. What's working had the fewest points (Table 2). However, the fact that current resources are even available, accessible and updated was a very popular response. It was highlighted that such resources provide initial awareness and underline the importance of obtaining flood risk knowledge, particularly the national five-day flood forecast map (Environment Agency 2019a). A lot of workshop participants also liked the simple colour schemes used in current visualisation practices, particularly varying shades of blue used on governmental flood hazard and risk maps. It was also seen as favourable that most of the flood maps gave a clear indication of possible flood locations, available in either aerial or 2D street view. Areas were also 'searchable' and maps zoom-able. Participants particularly stressed a potential for all maps to be brought together into one single platform or facility.

With regards to what could be better (Table 2), participants indicated there were too many national assumptions, and unique local parameters/maps need to be available. Current terminology used is confusing with too many different terms used to describe the same attribute. It was suggested that terminology needs to be thought through carefully and used coherently. The terms Flood Zones 1, 2 and 3 and return periods were underscored as being particularly perplexing. Participants also highlighted that tidal flood risk maps need more filters/layers rather than just one layer, e.g. extent of tidal flooding (Environment Agency 2019 b). Key buildings also need to be clearly identified, and potential flood impacts need to be available via interactive features, e.g. hovering links/captions could be used to obtain vital impact information.

Finally, participants identified many vital aspects/features missing from current available flood risk maps (Table 2). Highlighting points such as the lack of detail within available maps, i.e. vulnerability/risk-how has this been measured and what this means? Participants also noted a need for plain English/clarity, dates of revision, direction to next steps 


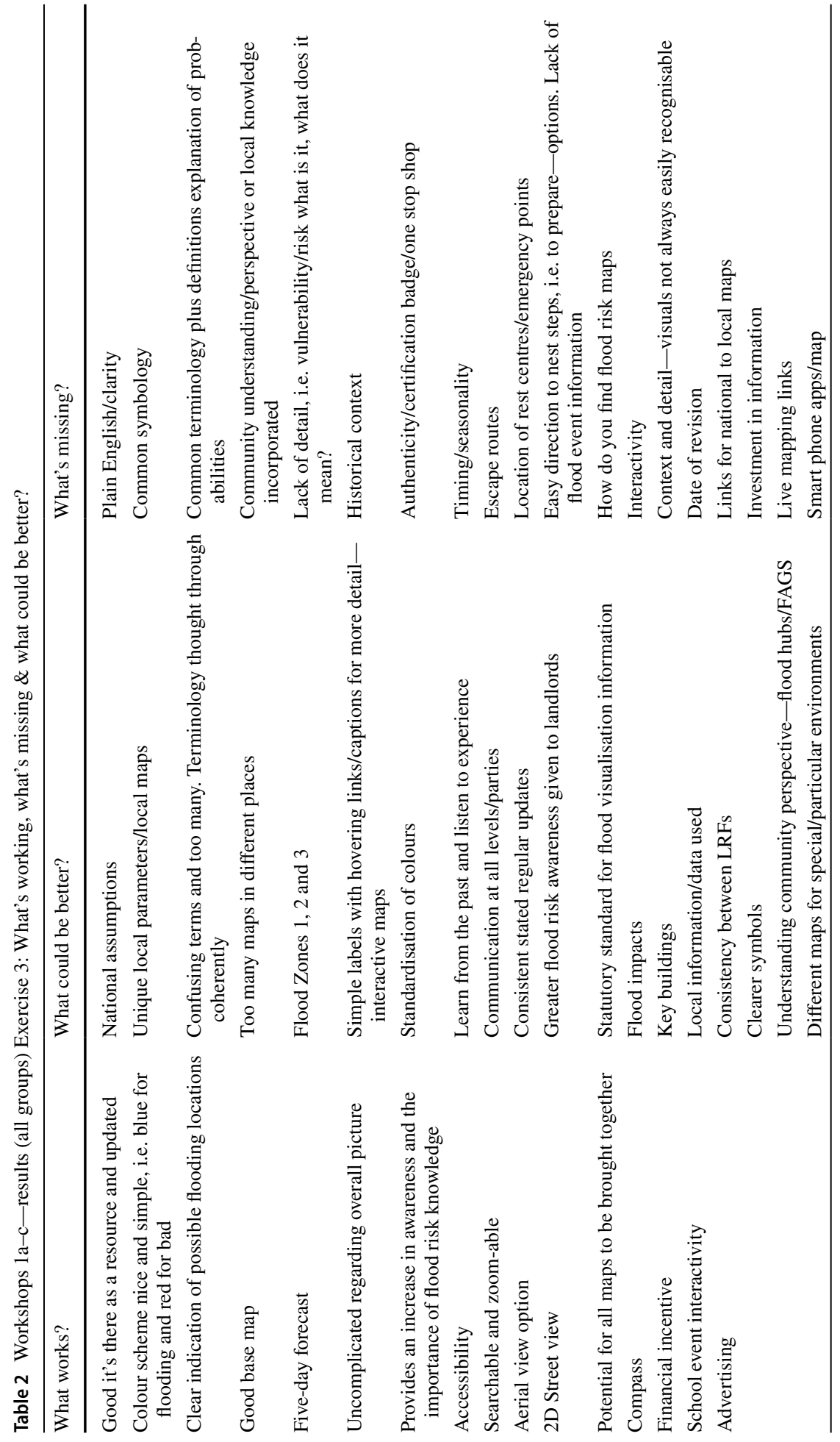




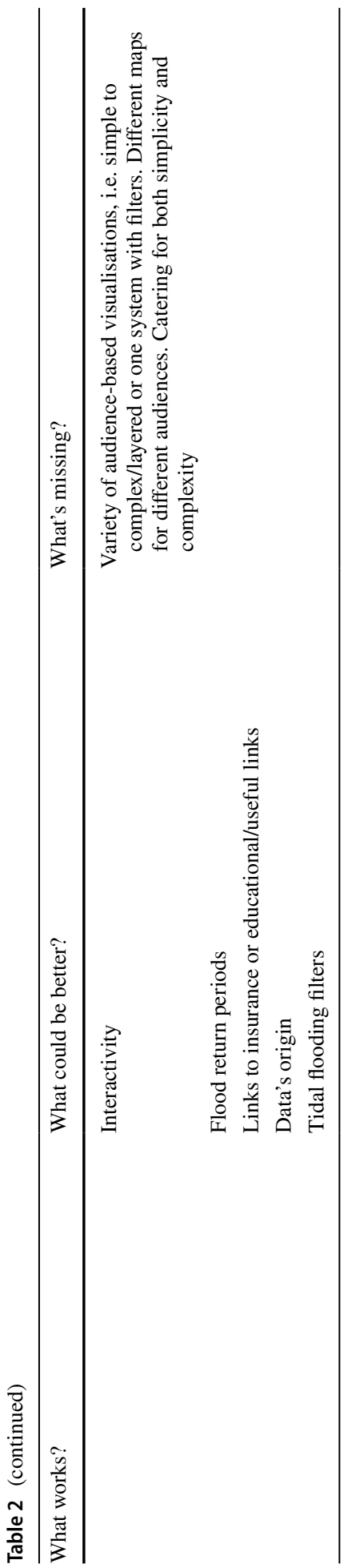


including flood preparation/event options, common symbology, explanation of terms and definitions - particularly probabilities, and, vitally, links to national and local maps with a variety of user-based visualisations, i.e. different maps for different users, catering for both simplicity and complexity. Participants also underlined the need for community understanding/perspective or local knowledge to be incorporated, including local content, e.g. which buildings are the most essential to the local community. It was also stressed that maps need a stamp of authenticity/certification, i.e. 'one stop shop'/resource you can trust. As currently there is a vast amount of misleading, unreliable and varied flood risk visualisation available to the public. These resources give very little explanation to how they were formed and what they actually mean/represent.

\subsection{Exercise 3: common flood risk visualisation themes and criteria}

Results for Workshops 1a-c Exercise 3 were collated, and the main overarching theme established by all 3 groups was actually simplicity, i.e. future flood risk visualisation needs to be informative but delivers complex information to different users in simple formats. Five specific key themes/criteria were also identified by all 3 groups, including (in no particular order):

1. User-driven maps

2. Different visuals available for same data sets/problem

3. Terminology

4. A central hub of information

5. Community knowledge

The top flood risk visualisation criteria set out by the participants were in fact very general. The development of user-driven maps (Criteria 1) was identified as a real necessity. It was stated that these maps need to include available options/layers to cater for varying degrees of complexity, depending on the user, i.e. different maps for different audiences. The second key criteria were that alternative visuals are available to disseminate the same problem, i.e. maps do not always work (Criteria 2). All visuals also need consistent terminology, definitions and symbology (Criteria 3) and are held in a central hub, i.e. everything in the same place - a central hub of information with multiple outputs (Criteria 4). It was also highlighted that local/community knowledge needs to be integrated into flood risk visuals, particularly the availability of local maps holding essential local knowledge and understanding related to flooding, i.e. national assumptions do not always work at local levels (Criteria 5).

\subsection{Exercise 4: Questionnaire: Which criteria do key flood risk visualisation users need and what should that entail?}

All Exercise 4 results (on-site and online) were collated and are presented in Fig. 3a-d. Figure $3 \mathrm{a}$ and $\mathrm{b}$ highlights that the majority of critical flood risk visualisation users need user-driven maps (Criteria 1), particularly large and local business owners and communities. However, Criteria 1 was voted as less essential for vulnerable homeowners, especially renters and the elderly. Furthermore, many of the participants noted (comments added to questionnaire) flood risk managers, engineers, planners and the EA did not need userdriven maps, as it is a resource they already have. Workshop 2 participants also highlighted 
(a)

$100 \%$

Criteria 1 - User Driven Maps. Different levels of detail available for different end users

$90 \%$

$80 \%$

$70 \%$

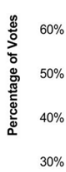

$30 \%$

$20 \%$

$10 \%$

$0 \%$

Flood Risk

Coastal

Planners

Fire

Police

Ambulance Communities Tourists Elderly

Flood risk Visualisation Users

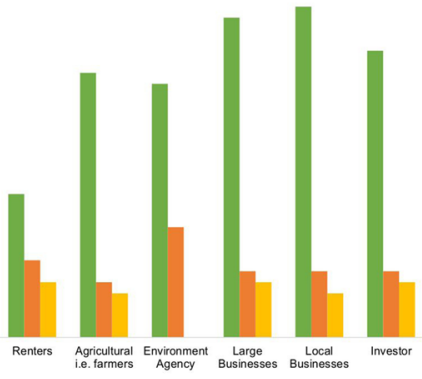

mYes $\quad$ No "Not Sure

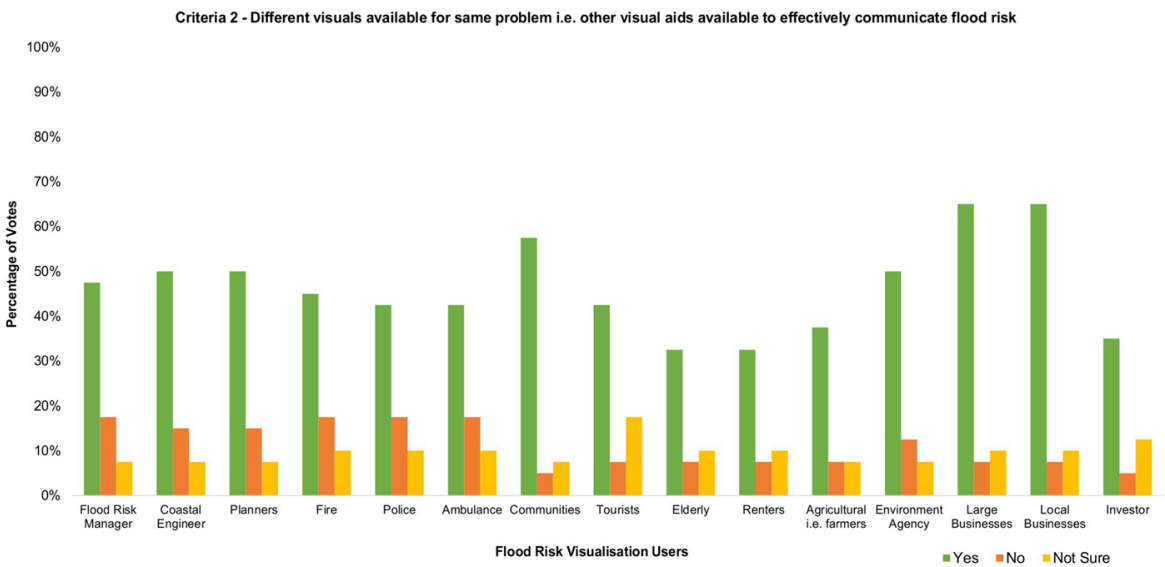

$100 \%$

Criteria 3 - Terminology: common terms and definitions to effectively communicate flood risk
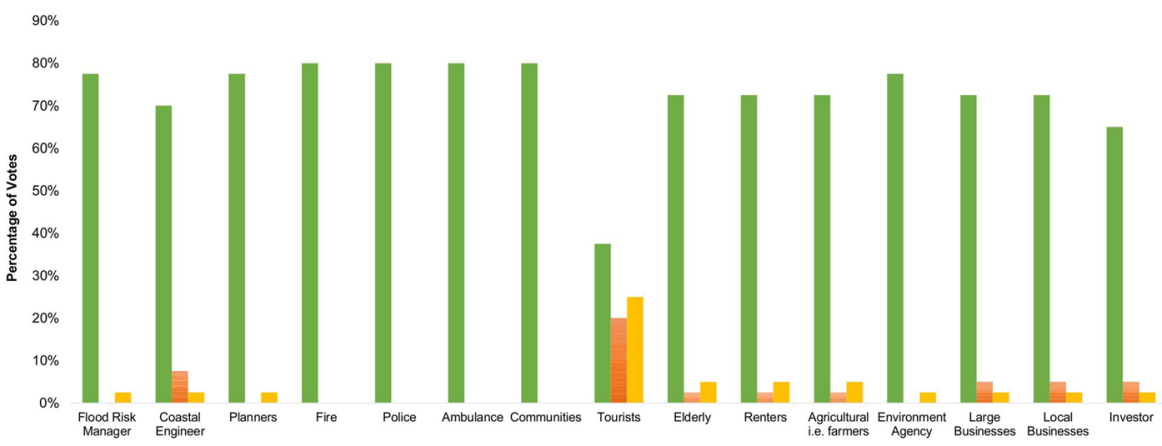

Flood Risk Visualisation Users

$=$ Yes $=$ No $=$ Not Sure

Fig. 3 a Workshop 2 Exercise 4-Do all key flood risk visualisation users need criteria 1, 2 and 3? b Workshop 2 Exercise 4-What should criteria 1, 2 and 3 entail depending on the flood risk visualisation user? c Workshop 2 Exercise 4-Do all key flood risk visualisation users need criteria 4 and 5? d Workshop 2 Exercise 4-What should criteria 4 and 5 entail depending on the flood risk visualisation user? 
(b)

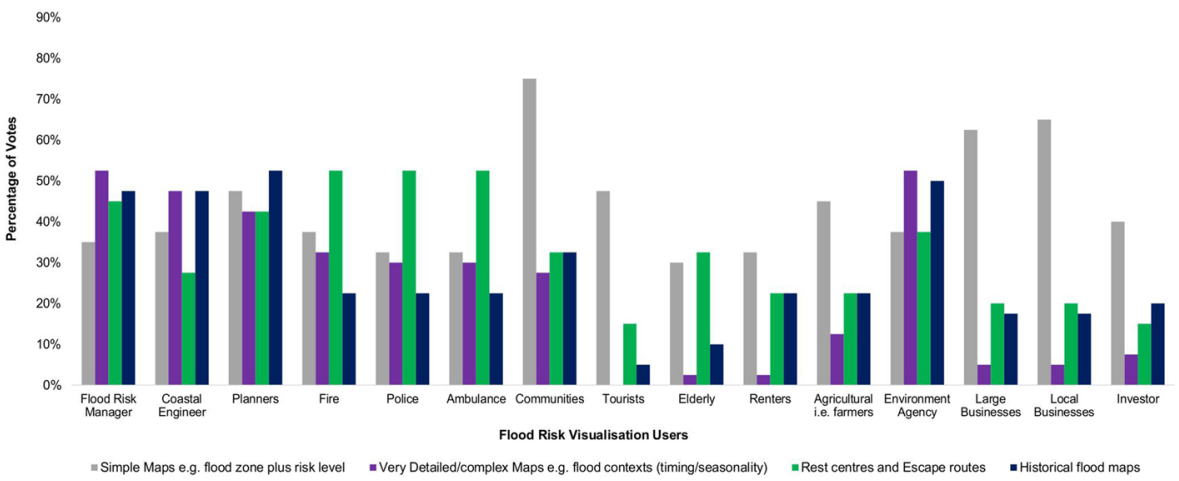

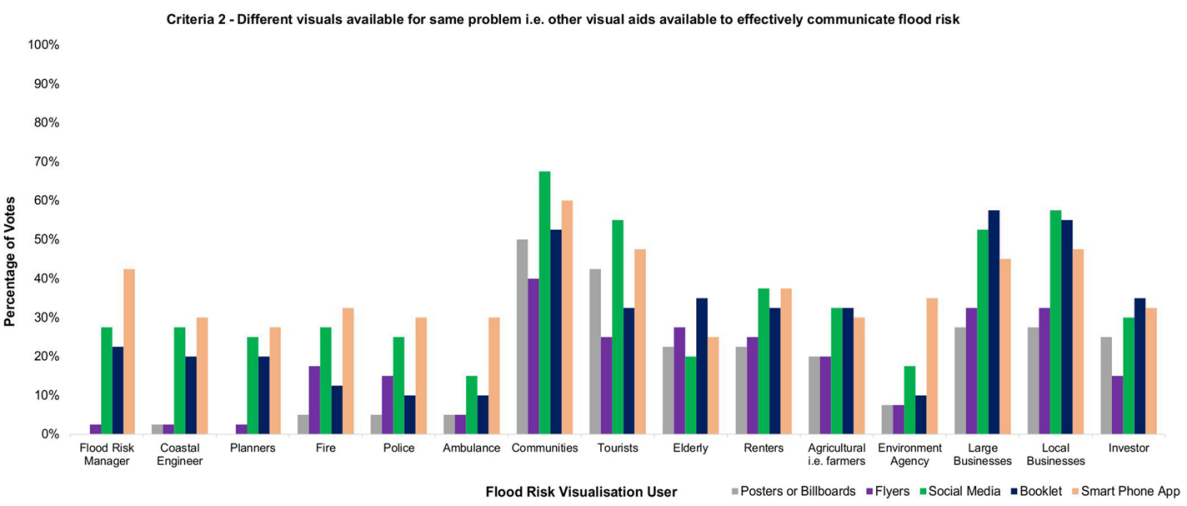

Criteria 3 - Terminology: common terms and definitions to effectively communicate flood risk

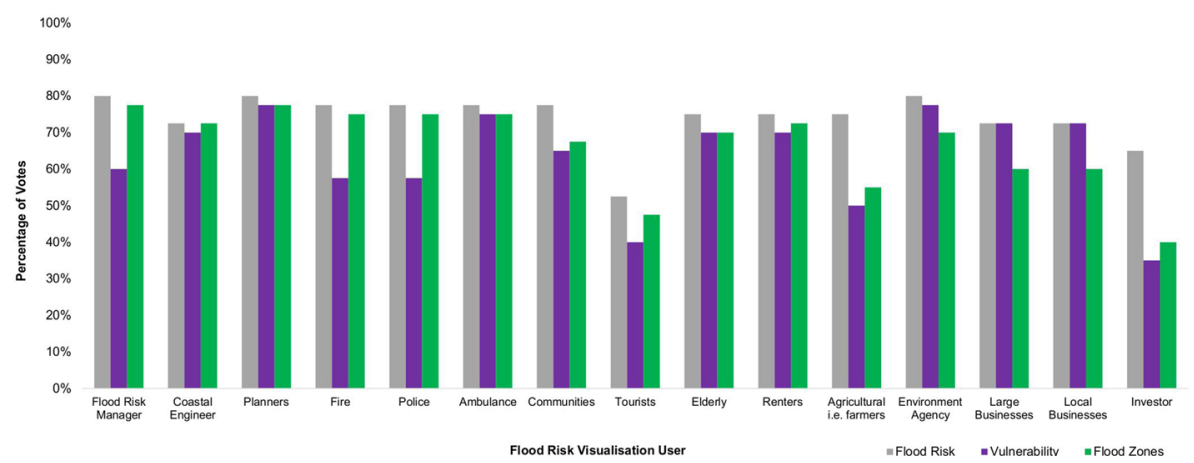

Fig. 3 (continued)

that it is essential that communities have simple flood maps available (75\% of the vote) and detailed/complex maps are more suited to flood risk managers, EA, engineers and planners, but not tourists, renters or the elderly. Just over half of Workshop 2 participants voted that all emergency responders need maps that pinpoint rest centres and escape routes, and 


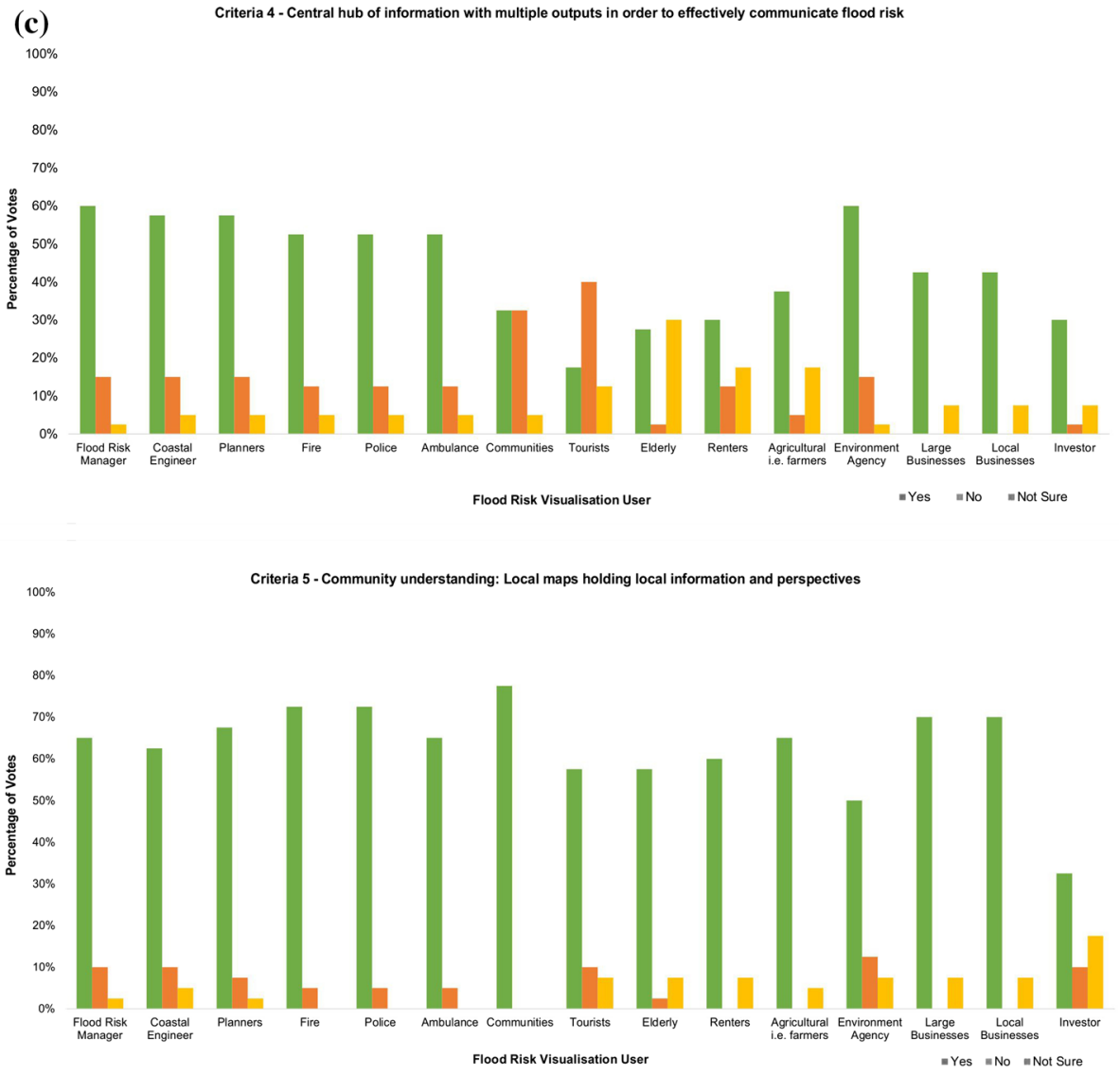

Fig. 3 (continued)

historical flood maps should be available to planners and the EA, not, however, to tourists or the elderly ( $\geq 10 \%$ of the votes).

The results for Criteria 2 (Fig. 3a and b) underline different visuals should particularly be available for large and local business owners and communities. Workshop 2 participants also identified this service might not be necessary for the EA, as $30 \%$ of the participants voted no or not sure, and $20 \%$ of the participants did not vote at all for this user. Communities were highlighted as the user that vitally needs alternative visuals available to help them understand flood risk, including social media, smart phone apps, booklets and posters/billboards. These were all voted $(>40 \%)$ as suitable effective alternative visual aids for communicating flood risk to this user, especially social media and smart phone apps. The results also highlighted that posters/billboards and flyers are an inappropriate alternative visual aid for local authorities, emergency responders and the EA, as are booklets for emergency responders and the EA. However, posters/billboards, social media and smart phone apps would be of use for tourists and the two latter aids should be considered for large and local businesses. Participants also separately noted for Criteria 1 and 2 that what should be visualised depends on vulnerability levels, types of business owners, continuity, intent/type of business/and culture. There is also a need for a clarification of what maps are 


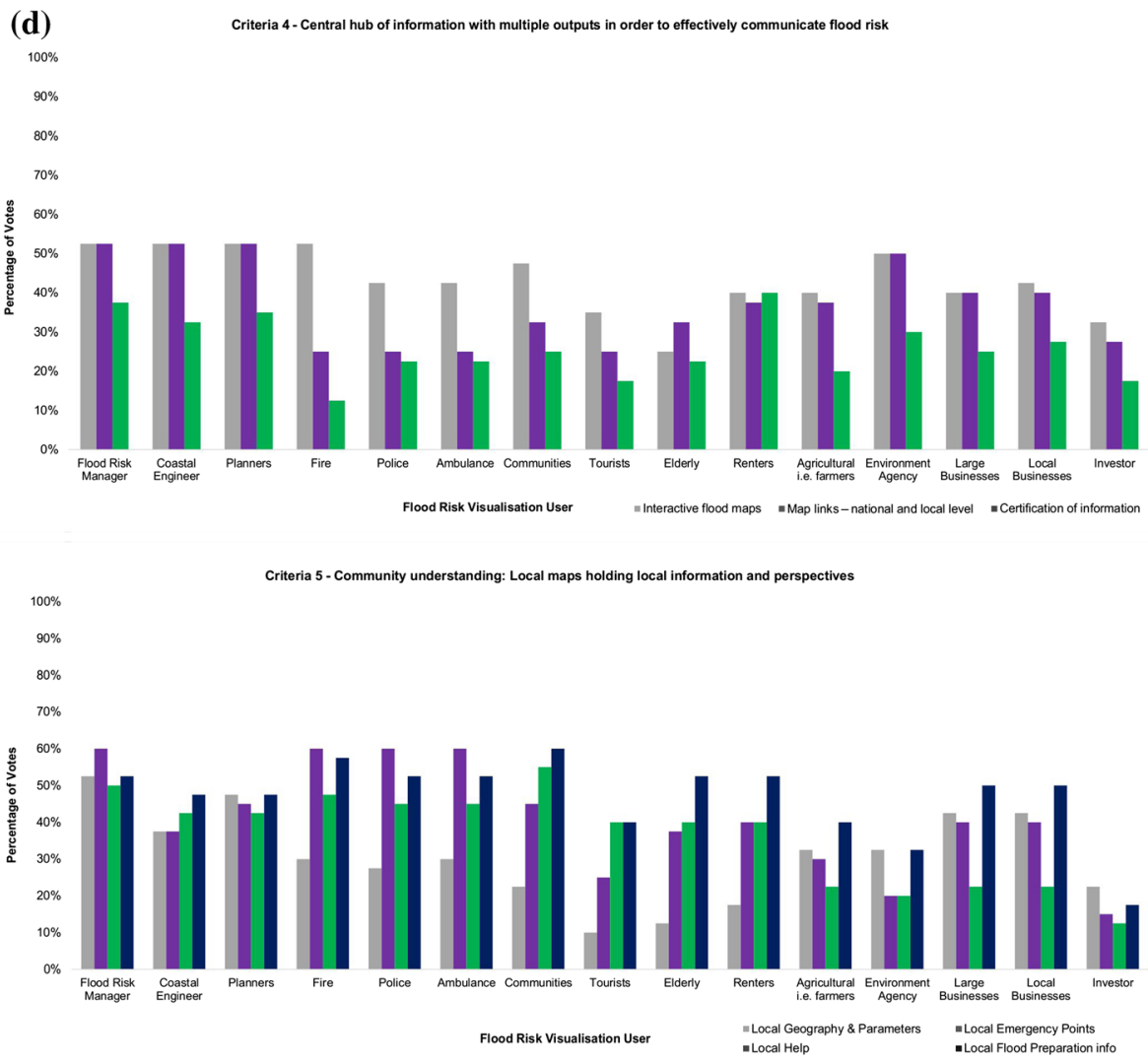

Fig. 3 (continued)

actually wanted and consultation is needed with individuals and groups, depending on user categories.

For Criteria 3 (Fig. 3a and b), participants emphasised that common terms and definitions are a necessity for almost all key flood risk visualisation users, particularly communities, emergency responders, EA, flood risk managers, planners, vulnerable homeowners, and large and local business owners. The term flood risk was highlighted to be the term or definition that predominantly key flood risk visualisation users need to understand; however, the term vulnerability is an essential term mainly for EA, planners and the ambulance service, not tourists or investors. Flood zones is a term that local authorities, emergency responders, EA, renters and the elderly need to understand, but this is not an essential term for investors, agricultural vulnerable homeowners or tourists. Workshop 2 participants also commented that currently none of the terms really work for the general public and perhaps the terms high, medium, low or very low risk with added descriptors would be more suitable.

Results for Criteria 4 (Fig. 3c and d) highlighted that the users EA, flood risk managers, engineers and planners need a central hub of information with multiple outputs more than any other user. However, Workshop 2 participants were divided on whether this is an essential flood risk visualisation criteria for communities $(67.5 \%$ voted either no or not 
sure). Furthermore, $40 \%$ of the participants felt this was not a criterion needed for tourists. Interactive flood maps were a popular choice and voted highly as something a central hub should provide for most users, particularly LA, fire service personnel, EA and communities. Map links to national and local resources (e.g. national and local flood data/information) were also identified as another effective tool to consider for LA and EA users and large and local business owners. The results also stress that certification of information would be very effective for renters and LA.

Community understanding (Criteria 5) was predominantly identified (Fig. 3c and d) as a flood risk visualisation criteria that would be very effective for the majority of critical flood risk visualisation users, specifically fire, police, large and local business owners, but principally communities. Workshop 2 participants also pinpointed investors as the user where this criterion might not be essential. Local geography and parameters (e.g. local geology, permeability, land use, population) was identified as an effective tool for flood risk managers and planners, but not for tourists, elderly or renters. However, local flood preparation information was a popular option and was determined to be the type of information that needs to be available to the majority of the key flood risk visualisation users, particularly communities, emergency responders, elderly, renters and large and local business owners. Finally, local emergency points were identified as a necessity for flood risk managers, communities and all emergency responders, whereas Workshop 2 participants deduced local help, i.e. flood/welfare groups would be of most use to communities, flood risk managers and emergency responders. The elderly and renters were also highlighted as two users that might need this tool. This resource, however, was not seen as useful for investors, a user group that collectively had the lowest number of votes for Criteria 5 and what information this criterion should entail.

\section{Discussion}

Flood events are a significant challenge for many human societies and one that is expected to increase in both frequency and impact (Adikari and Yoshitani 2009; Birkholz et al. 2014). Current flood risk visualisation practices, especially accessible flood risk maps, frequently do not communicate flood risk in an understandable or useful way (Rollason et al. 2018). Yet the research undertaken and presented within this paper confirms it is possible to implement changes and execute effective flood risk communication, meeting critical users' needs. This is imperative as responsibilities of flood resilience are shifting more onto those at risk (Rollason et al. 2018), enhancing the need for the communication of flood risk (particularly flood risk mapping) to be successful. Effective communicative actions/practices can significantly improve community resilience via enhanced understanding of possible future threats, identification (opportunity mapping) of vulnerable areas and/or areas at risk, and knowledge of individual flood adaptive options/processes. Findings from the initial UK Urban Flood Risk Communication workshops presented within this article identify the direction national and local future visualisations should take, who needs them most, and depending on the user, what that should entail. These recommendations can provide direction to enable those responsible to proactively address flood risk and help improve the resilience of at-risk communities.

Workshops $1 \mathrm{a}-\mathrm{c}$ and 2 findings uniquely identified key flood risk visualisation users (i.e. those that that need this facility more than most) who need to be considered when establishing future flood risk visualisations. In fact, the results highlighted there are 
many high priority flood risk visualisation users (local authorities, emergency services, specific members of the public, i.e. elderly, renters etc.) and crucially they share and need key criteria (Table 3 ) that current flood risk visualisation is not delivering. In fact, the results (Workshop 2) highlighted that the different users have similar or very dissimilar requirements. However, for the user group communities only when all of the identified key criteria is practiced will flood risk visualisation successfully communicate flood risk to this critical user. In fact, the results from Workshop 2 crucially highlight why current communication practices to communities are not always effective, as key provisions/features are missing, emphasising that not only are the requirements of this user greater, but they also are more complex. Large and local business owners, LA, fire services, police and EA were also identified via Workshop 2 as flood risk visualisation users that predominantly need the majority of this key criteria, whereas investors and tourists were identified to have fewer requirements, e.g. a central hub of information was not perceived as an essential requirement for tourists and investors do not really need local/community knowledge. User-driven maps were also not seen as a resource needed by the elderly or renters.

The other critical overarching theme that was established during Workshops $1 \mathrm{a}-\mathrm{c}$ and 2 is the need for overall simplicity and consistency, a practice current flood risk visualisation approaches are not undertaking. In fact, presently there are many flood risk map services available to the public, from a variety of sources (governmental, insurance, private), communicating different messages (threat, vulnerability, risk, defences/no defences) with little or too much explanation. This is not only overwhelming, but also confusing, potentially resulting in further misunderstanding of flood risk which is detrimental to flood resilience. Nevertheless, many of the key flood risk visualisation criteria identified and presented in this paper (Table 3) reiterate key messages from the recent Flood Risk Communications Public Dialogue project (2015) funded via the EA and Sciencewise, the IPCC report (2012) and other flood communication studies (Haer et al. 2016), including being conscious of the needs of different users (Criteria 1 and 2); one size does not fit all-proliferation of different routes for conveying core key messages needed, as maps are not always helpful (Criteria 2); be clear about risk and its potential impacts, i.e. do not assume information will scare people (Criteria 3); do not describe probability and risk in mathematical language (Criteria 3); language needs to be simple, clear and precise (overarching theme and Criteria 3); be clear of preventative actions that can/should be taken (Criteria 5); highlight what type of help is available (Criteria 5); and focus on making information have a local and historical context (Criteria 5) (Warburton 2016).

Table 3 Key flood risk visualisation criteria established in Workshops $1 \mathrm{a}-\mathrm{c}$ and 2

\begin{tabular}{ll}
\hline Key flood risk visualisation criteria & Description \\
\hline Criteria 1-user-driven maps & $\begin{array}{c}\text { User-driven maps with varying degrees of complexity depending on } \\
\text { the end user }\end{array}$ \\
$\begin{array}{cc}\text { Criteria 2-different visuals avail- } \\
\text { able for same data sets/problem }\end{array}$ & $\begin{array}{c}\text { Different visuals available for the same problem for different users, i.e. } \\
\text { maps do not always work }\end{array}$ \\
$\begin{array}{c}\text { Criteria 3-terminology } \\
\text { Visuals with consistent use of terminology, symbology and definitions } \\
\text { mation }\end{array}$ & $\begin{array}{c}\text { Many critical users need an obvious central hub of information that } \\
\text { holds multiple outputs }\end{array}$ \\
Criteria 5-community knowledge & Visuals that utilise community/local knowledge and understanding
\end{tabular}


However, there are opportunities to further develop this study, particularly regarding Criteria 2 and 4. Criteria 1 (user-driven), Criteria 3 (terminology) and Criteria 5 (community knowledge) received more responses than any of the other criteria for Workshop 2 's questionnaire (Exercise 4). 35\% of Workshop 2 participants (Group 4) did not vote for any of the questions associated with Criteria 2 (different visuals for the same problem) or 4 (central hub of information). Suggesting that either, these particular criteria (2 and 4) compared to the others (1, 3 and 5) were not seen to be as necessary for effective future flood risk visualisation, or the right questions/options were not asked/available in Workshop 2. For example, participants highlighted that the user group vulnerable homeowners (elderly, renters and agricultural) might not need available alternative forms of visual aids in order for them to understand flood risk. However, users such as the elderly have concerns (too much technology and too complex), barriers (cost, lack of understanding) and scepticism (general negativity) towards the use of modern technology, particularly computers (Whitcomb 1990; Vaportzis et al. 2017), meaning that online flood maps, smart phone apps or social media in reality might not be the most suitable agents of communication for this user. Highlighting further investigation is needed regarding this criterion (2) and user, i.e. other forms of communication are needed (investigated) rather than visualisation techniques for this critical user, such as door-to-door conveyance. Furthermore, although a central hub of information (Criteria 4) appears to be a new flood risk visualisation criterion that has emerged via this project, this resource to a point already exists via the governmental website (GOV.UK 2019), where there are maps for flood warning, urban planning and flood risk (five-day flood forecast and long-term flood risk). Hence why stakeholders that comprised the Flood Risk Communications Public Dialogue project (2015) Oversight Group and members of Group 4 (all are whom from a flood risk management/governmental/hazard background) might not have identified this as an essential new requirement. However, the entirety of these resources was mostly unknown to the rest of the UK Urban Flood Risk Communication Workshop participants, particularly members of Groups 2 and 3 and some of Group 1. Highlighting this resource is perhaps not obvious enough and needs to be markedly sign posted (media, social media). Additionally, the available maps are not compiled in one place (i.e. layers contained in one map tool), but found via separate links and are not clear whether they are specifically user driven. Furthermore, these maps hold different, potentially confusing, information. The map for planning describes flooding in the context of flood zones where flood defences are not considered, whereas the flood risk maps describe flooding in the context of high, medium, low and very low risk, where flood defences are considered but with no real explanation to what risk actually means. However, advantageously the long-term flood risk map does have the options to view in either basic or detailed format, providing users with the option to acquire further information. But, where there are many layer options available for the hazard surface water flooding (potential water depth, velocity, direction of flow, different risk levels, etc.) there is only one flood extent layer available for rivers and sea, whichever view format (basic or detailed) is selected. With no further information provided, there is a lack of detail provided for rivers and sea flood risk, yet with more information available, more individuals potentially will take action.

Other studies (Keller et al. 2006; Bell and Tobin 2007; Kriebich et al. 2009) have made some recommendations towards technical aspects of flood risk communication, including preferred flood probability formats, perceived uncertainty and information preferences (Rollason et al. 2018). However, the results from this research accentuate future flood risk communication needs to focus more on flood risk visualisation's ability to link individuals and communities to the understanding of their risk of flooding, the potential implications, 
and crucially the actions that need to be taken. Rather than concentrating on technical, statistical or map-based aspects of flood risk visualisation, community/local knowledge needs to be integrated to ensure local flood risk maps hold essential local information (welfare groups/emergency information) and knowledge (flood preparation) for local understanding, reducing, sometimes, ineffectual national assumptions. The inclusion of more detail via local flood information has great potential to increase local flood risk awareness (Haer et al. 2016) and enhance understanding of flood roles and responsibilities, thereby educating communities (particularly vulnerable ones). This level of detail can also help inaugurate confidence through vulnerable communities embedding understanding of available support and individual responsibility.

Finally, the results from these workshops have also highlighted the possible achievements via collaborative approaches and public dialogue groups when co-creating new ways of conveying information about flood risk, with stakeholders of varying flood experiences (particularly members of the community, i.e. Groups 2 and 3). The workshops provided a space and stage for knowledge exchange between experts and non-experts, unearthing new flood risk visualisation criteria, reaffirming criteria/themes that need to be implemented and identifying key users and what criteria these users need. The workshops have also helped build capacity, understanding and relationships and networks between the flood stakeholders that participated, strengthening links that potentially could lead to the application of this collective knowledge to their communities and co-design new communication practices of flood risk.

\section{Conclusion}

To conclude, there is critical need and responsibility to ensure flood risk communication is appropriate for public audiences, in order to develop and promote better understanding of flood risk. Yet current awareness and understanding of flood risk is very low and past flood risk communication projects have concentrated too heavily on the technical and map-based peculiarities of flood risk visualisation. The results presented in this paper have highlighted the level of insights stakeholders can provide and that the majority of issues with current flood risk visualisation approaches are still predominantly at a base level. However, this research has confirmed that flood risk visualisation still holds great potential to be the main vehicle for engaging and delivering information about flood risk, but depending on the user certain particularities need to be considered. There is now a real opportunity to redevelop our platform and methodologies/practices for flood risk visualisation (i.e. central hub with one terminology and delivery), to constructively visualise/convey flood risk into simplified images that can also offer complexity, localised information and meaning to different users. The findings of this study have thus resulted in approaches that crucially help connect the user (of which there are many, some more critical than others) to the threat they are facing, what that means to the individual and their community, and the individual and local actions that need to be taken in order to embed and enhance resilience in flood-prone communities.

Acknowledgements We wish to thank the Royal Geographic Society (with IBG) for their support and their Environment and Sustainability Small Research Grant [05/17] that funded this research. We also wish to thank all the workshop participants for giving us their valuable time, comments, suggestions and ideas.

Funding This work was supported by the Royal Geographical Society (with IBG), Kensington, London [05/17]. 
Conflict of interest No potential conflict of interest was reported by the authors.

Ethical Statement The ethical application for the project UK Urban Flood Risk Communication was reviewed by an Ethics Committee (Technology Faculty Ethics Committee, University of Portsmouth) between the dates of 21/6/17 and 4/7/17. Discussions did not raise any significant ethical issues, and the documentation was considered to be well presented. Furthermore, all data collected in this study were anonymised and whilst participants were identified via their organisation, it was not possible to actually identify individuals of the organisation. Participants were also free to withdraw from the project at any point.

Open Access This article is licensed under a Creative Commons Attribution 4.0 International License, which permits use, sharing, adaptation, distribution and reproduction in any medium or format, as long as you give appropriate credit to the original author(s) and the source, provide a link to the Creative Commons licence, and indicate if changes were made. The images or other third party material in this article are included in the article's Creative Commons licence, unless indicated otherwise in a credit line to the material. If material is not included in the article's Creative Commons licence and your intended use is not permitted by statutory regulation or exceeds the permitted use, you will need to obtain permission directly from the copyright holder. To view a copy of this licence, visit http://creativecommons.org/licenses/by/4.0/.

\section{References}

Adger WN (2006) Vulnerability. Glob Environ Chang 16(3):268-281

Adikari Y, Yoshitani J (2009) Global trend in water-related disasters—an insight for policymakers. UNESCO, Paris

Amann J, Rubinelli S (2017) Views of community managers on knowledge co-creation in online communities for people with disabilities: qualitative study. J Med Internet Res 19(10):e320. https://doi. org/10.2196/jmir.7406

Anderson A, Hardwick J (2017) Collaborating for innovation: the socialised management of knowledge. Int Entrep Manag J 13:1181-1197. https://doi.org/10.1007/s11365-017-0447-6

Bell HM, Tobin GA (2007) Efficient and effective? The 100 year flood in the communication and perception of flood risk. Environ Hazards 7(4):302-311. https://doi.org/10.1016/j.envhaz.2007.08.004

Birkholz S, Muro M, Jeffrey P, Smith HM (2014) Rethinking the relationship between flood risk perception and flood management. Sci Total Environ 478:12-20. https://doi.org/10.1016/j.scitotenv.2014.01.061

Bodoque JM, Diez-Herrero A, Amerigo M, Garcia JA, Ocina J (2019) Enhancing flash flood risk perception and awareness of mitigation actions through risk communication: a pre-post survey design. J Hydrol 568:769-779. https://doi.org/10.1016/j.jhydrol.2018.11.007

Bracken LJ, Oughton EA, Donaldson A, Cook B, Forrester J, Spray C, Cinderby S, Passmore D, Bissett N (2016) Flood risk management, an approach to managing cross-border hazards. Nat Hazards 82:217240. https://doi.org/10.1007/s11069-016-2284-2

Butler C, Pidgeon N (2011) From 'flood defence' to 'flood management': exploring governance, responsibility, and blame. Environ Plan C Gov Policy 29:533-547. https://doi.org/10.1068/c09181j

Callon M (1999) The role of lay people in the production and dissemination of scientific knowledge. Sci Technol Soc 4(1):81-94

Cinderby S, Forrester J (2005) Facilitating the local governance of air pollution using GIS for participation. Appl Geogr 25:143-158. https://doi.org/10.1016/j.apgeog.2005.03.003

Clarke J, Wicks J, Lovell L, Han D, Davis J (2014) Keep it simple: user-focused flood risk visualisation. P I Civil Eng-Civ Eng 167:41-48. https://doi.org/10.1680/cien.13.00016

Cornwall Council (2015) cornwall flood resilience pathfinder-final project March 2015. National Flood Forum. https://www.cornwall.gov.uk/media/12361015/Flood-Pathfinder-Final-Report-web.pdf. Accessed 4 January 2016

de Moel H, van Alphen J, Aerts JCJH (2009) Flood maps in Europe - methods, availability and use. Nat Hazard Earth Sys Sci 9:289-301. https://doi.org/10.5194/nhess-9-289-2009

Demeritt D, Nobert S (2014) Models of best practice in flood risk communication and management. Environ Hazards 13(4):313-328. https://doi.org/10.1080/17477891.2014.924897

Douglas I, Garvin S, Lawson N, Richards J, Tippett J, White I (2010) Urban pluvial flooding: a qualitative case study of cause, effect and non-structural mitigation. J Flood Risk Manag 3(2):112-125. https:// doi.org/10.1111/j.1753-318X.2010.01061.x 
Eden C, Ackermann F, Bryson J, Finn C, Andersen D, Richardson G. (2006) Experiences in attempting to combine group support methods. In: Group decision and negotiation international conference,June 2006, Karlsruhe, Germany, pp 25-28

Environment Agency (2016) Written evidence from the Environment Agency (FFP 128). Publication Parliament UK. http://data.parliament.uk/WrittenEvidence/CommitteeEvidence.svc/EvidenceDocument/Env ironment,\%2520Food\%2520and\%2520Rural\%2520Affairs/Future\%2520Flood\%2520Prevention/written/30965.html. Accessed 6 November 2017

Environment Agency (2019a) 5-day flood risk for England and Wales. GOV.UK. https://flood-warninginformation.service.gov.uk/5-day-flood-risk. Accessed 6 November 2017

Environment Agency (2019b) Learn more about flood risk. GOV.UK. https://flood-warning-informatio n.service.gov.uk/long-term-flood-risk/map. Accessed 6 November 2017

Frantzeskaki N, Kabish N (2016) Designing a knowledge co-production operating space for urban environment governance-Lessons from Rotterdam, Netherlands and Berlin Germany. Environ Sci Policy 62:90-98. https://doi.org/10.1016/j.envsci.2016.01.010

GOV.UK (2019) Flooding and coastal change. GOV.UK. https://www.gov.uk/topic/environmentalmanagement/flooding-coastal-change. Accessed 6 November 2017

Haeberling C (2004) Cartographic design principles for 3D maps-a contribution to cartographic theory. 22nd International Cartographic Conference

Haer T, Botzen WJ, Aerts CJH (2016) The effectiveness of flood risk communication strategies and the influence of social networks-Insights from an agent-based model. Environ Sci Policy 60:44-52

Hagemeier-Klose M, Wagner K (2009) Evaluation of flood hazard maps in print and web mapping services as information tools in flood risk communication. Nat Hazard Earth Sys Sci 9:563-574. https ://doi.org/10.5194/nhess-9-563-2009

House of Commons: Environment, Food and Rural Affairs Committee (2016) Future Flood Prevention Report. Publications Parliament UK. https://publications.parliament.uk/pa/cm201617/cmselect/ cmenvfru/115/115.pdf. Accessed 31 October 2017

IPCC (2012) Managing the risks of extreme events and disasters to advance climate change adaptation. Cambridge University Press, Cambridge. doi:10.1017/CBO9781139177245

Kellens W, Terpstra T, De Maeyer P (2013) Perception and communication of flood risks: a systematic review of empirical research. Risk Anal 33(1):24-49. https://doi.org/10.111 1/j.1539-6924.2012.01844.x

Keller C, Siegrist M, Gutscher H (2006) The role of the affect and availability heuristics in risk communication. Risk Anal 26(3):631-639. https://doi.org/10.1111/j.1539-6924.2006.00773.x

Kreibich H, Thieken AH, Grunenberg H, Ullrich K, Sommer T (2009) Extent, perception and mitigation of damage due to high groundwater levels in the city of Dresden, Germany. Nat Hazard Earth Sys Sci 9:1247-1258

Maantay J, Maroko A (2009) mapping urban risk: flood hazards, race, and environmental justice in New York. Appl Geogr 29(1):111-124. https://doi.org/10.1016/japgeog.2008.08.002

Maskrey SA, Mount NJ, Thorne CR, Dryden I (2016) Participatory modelling for stakeholder involvement in the development of flood risk management intervention options. Environ Model Softw 82:275-294. https://doi.org/10.1016/j.envsoft.2016.04.027

Meyer V, Kuhlicke C, Luther J et al (2012) Recommendations for the user-specific enhancement of flood maps. Nat Hazard Earth Syst 12:1701-1716

National Flood Forum (2016) At risk of flooding? National Flood Forum. https://www.nationalfloodfo rum.org.uk/at-risk-of-flooding-2/. Accessed 6 January 2016

Pegg D (2013) Design issues with 3D maps and the need for 3D cartographic design principles. Lazarus Elite. https://lazarus.elte.hu/cet/academic/pegg.pdf. Accessed 1 September 2015

Percival S (2016) Portsmouth coastal flood vulnerability and risk: assessment and mapping of impacts at microscale. Dissertation, University of Portsmouth. Research Portal. https://researchportal.port. ac.uk/portal/files/5488234/spercival_thesis.pdf Accessed 17 July 2018

Percival S, Gaterell M, Teeuw R (2018) Urban neighbourhood flood vulnerability and risk assessments at different diurnal levels. J Flood Risk Manage 12(3):e12466. https://doi.org/10.1111/jfr3.12466

Percival S, Teeuw R (2019) A methodology for urban micro-scale coastal flood vulnerability and risk assessment and mapping. Nat Hazards 97(1):355-377. https://doi.org/10.1007/s11069-019-03648-7

Petrovič D, Mašera P (2005) Analysis of user's response on 3D cartographic presentations, in: Proceedings of the 22nd ICA International Cartographic Conference, A Coruña, Spain.

Pitt M (2008) Learning Lessons from the 2007 Floods - Full Report. National Archives. https://webar chive.nationalarchives.gov.uk/20100807034701/http:/archive.cabinetoffice.gov.uk/pittreview/thepi ttreview/final_report.html. Accessed 17 July 2018 
Porter J, Demeritt D (2012) Flood-risk management, mapping, and planning: the institutional politics of decision support in England. Environ Plann A 44(10):2359-2378. https://doi.org/10.1068/a44660

RSPB (2016) Flooding in Focus-Recommendations for more effective flood management in England. RSPB. https://www.rspb.org.uk/Images/flooding-in-focus_tcm9-386202.pdf. Accessed 6 January 2016

Rollason E, Bracken LJ, Hardy RJ, Large ARG (2018) Rethinking flood risk communication Nat Hazards 92:1665-1686. https://doi.org/10.1007/s11069-018-3273-4

Sciencewise (2014) What does flood risk mean? Co-creating new risk communications with the public. ASCE Library. https://sites.cardiff.ac.uk/secg/files/2016/03/Paper-4-Communicating-Flood-RiskProject-Overview.pdf. Accessed 14 January 2019

Vaportzis E, Clausen MG, Gow AJ (2017) Older adults perceptions of technology and barriers to interacting with tablet computers: a focus group study. Front Psychol 8:1687. https://doi.org/10.3389/fpsyg .2017 .01687

Wamsler C (2016) From risk governance to city-citizen collaboration: capitalising on individual adaptation to climate change. Environ Policy Gov 26:184-204. https://doi.org/10.1002/eet.1707

Warburton D (2016) Tracing the impacts of public dialogue projects supported by Science wise: Flood risk communications. Evidence Environment Agency. https://webarchive.nationalarchives.gov.uk/20180 103170554/http://www.sciencewise-erc.org.uk/cms/assets/Publications/Sciencewise-Flood-Risk-dialo gue-impacts-March2016.pdf Accessed 26 April 2019

Whitcomb RG (1990) Computer games for the elderly. Conference on computers and the quality of life (CQL '90). Proceedings NY: ACM Press, pp 112-115.

Wicks J, Clarke J, Davis J, Han D, Lovell L (2014) Keep it simple: user-focused flood risk visualisation. Proc ICE: Civ Eng 167:41-48

Wilson L, O'Brien G, O'Keefe P, England K (2014) Barriers to Adaptation in Newcastle upon Tyne, UK: Preliminary Findings. Urban Climate 7:33-46. https://doi.org/10.1016/j.uclim.2013.10.003

Publisher's Note Springer Nature remains neutral with regard to jurisdictional claims in published maps and institutional affiliations. 